\title{
Efecto vudú: posmodernidad y la disolución de fronteras espacio-temporales en la narrativa fantástica mexicana de inicios del siglo XXI
}

\author{
Efecto vudú: Postmodernism and time-space border \\ dissolution in the Mexican narrative of fantasy \\ of the $21^{\text {st }}$ Century
}

TARIK TORres MojICA*

Resumen:

La realidad global de inicios de siglo XXI nos muestra un espacio cambiante, de entrecruces de bienes culturales, cosmovisiones y lenguajes. Este entorno suscita cambios en la forma de vida y, entre otros aspectos, también en las artes, incluyendo la literatura. La cultura global se manifiesta en la producción literaria en México no solo por los temas que aborda, sino también por el modo en que se singulariza la experiencia humana ante un entorno que cambia constantemente y en el que nociones como certeza y linealidad histórica se han sometido a tensión; en suma, en el que diversos marcos de referencia construidos por la Modernidad han entrado en crisis. Así, se observa en la literatura mexicana el desarrollo de formas discursivas como la policíaca, la novela negra, el horror y la ciencia ficción, que históricamente han cargado sobre sí la sospecha de ser expresiones menores, de poca valía estética y, más aun, de ser ajenas a la tradición cultural nacional.

En el presente artículo se hace una aproximación a la novela Efecto vudú de Edgar Omar Avilés, una obra construida con base

\footnotetext{
* Universidad de Guanajuato.
} 
en la hibridación textual, que discurre en la fragmentariedad y lo fantástico para desarrollar una historia en la que las nociones de tiempo, espacio, mito, magia y ciencia ficción se entremezclan. Para abordar esta obra se recurre primordialmente a la propuesta teórica sobre lo fantástico planteada por Omar Nieto en Teoría general de lo fantástico.

\section{Palabras clave:}

Literatura mexicana reciente, narrativa fantástica, posmodernidad, Edgar Omar Avilés, Efecto vudú.

\section{Abstract:}

Global reality from the beginning of the 21 st century presents itself as an ever-changing space of intersectional crosses of cultural goods, worldviews and languages. This environment generates changes in the way people conceive not just their lives, but, and among other aspects, also Art, including literature. This Global Culture is manifested in recent Mexican literature, not only by the topics it addresses, but also in the way it highlights human experience within a constantly changing environment; where notions of historical certainty and linearity have been subjected to tension. In short, the way in which the many parameters constructed under the Modern mental paradigm have entered a state of crisis. Thus, in Mexican literature new discursive forms such as detective and police narrative or, horror and science fiction genres, which have been considered as minor literary forms, of little aesthetic value, alien to national cultural tradition.

This paper approaches the novel Efecto vudú by Edgar Omar Avilés, as a work built upon textual hybridization, fragmentariness and the fantastic, to develop a story where notions of time, space, myth, magic and science fiction intermingle. For the purpose of this analysis, Omar Nieto's theoretical perspective of fantasy in narrative, as developed in his Teoria general de lo fantástico, will be primarily used.

Key words:

Contemporary Mexican Literature, Fantastic Narrative, Postmodernism, Edgar Omar Avilés, Efecto vudú. 


\section{Introducción}

Un elemento particular de nuestro tiempo es el desarrollo de la cultura global: el avance de las tecnologías de la información y de traslado de bienes y personas ha producido un vigoroso intercambio y consumo de elementos materiales y simbólicos. Ello ha provocado una profunda y drástica recomposición de las estructuras demográficas, ideológicas, culturales y lingüísticas de naciones enteras. Este fenómeno, aunque pareciera tener como consecuencia una homogenización en las formas de consumo y de producción de entidades simbólicas y materiales, ha resultado en nuevos sincretismos, porque los modelos locales y tradicionales entran en una dinámica de intercambio y diálogo complejo con estructuras y visiones provenientes de diversas latitudes.

Fenómenos como la globalización nos llevan a pensar cuál es el papel que tiene la narrativa fantástica en el presente: ¿por qué hoy por hoy resulta tan atractiva? Tal vez porque la realidad actual es tan desconcertante que bien vale la pena aproximarse a ella desde la imaginación, desde formas discursivas en las que, precisamente, se pone de manifiesto lo elusivo de la "verdad", lo contrastante y las complejidades del presente. $\mathrm{Al}$ respecto, Alberto Chimal, uno de los más prolíficos narradores de texto fantástico en México, señala:

la imaginación fantástica expresa . . nuestras aspiraciones, sueños y pesadillas, volviéndolos imágenes visibles . . . no exige, como se piensa a veces, el uso de ciertas tramas, de tales o cuales tipos de personaje... Es tan solo un recurso, como muchos otros al alcance de los narradores de todas las épocas, y puede usarse en muchos tipos de narraciones. (8-9)

No puede soslayarse el hecho de que en años recientes la pregunta sobre lo fantástico se ha convertido en un tema relevante por el número de obras que se han publicado en años recientes y que han sido relacionadas con este tipo de discurso y, además, por el modo como se ha vuelto necesario someter a reconsideración sus marcos de concepción y valoración. En el presente artículo se propone hacer una revisión de la noción de lo fantástico, partiendo 
de la propuesta de Omar Nieto en su Teoría general de lo fantástico, para posteriormente hacer una mirada panorámica y breve hacia lo que ha sido la producción de esta forma de discurso en las letras mexicanas. Al final, se hará una aproximación de análisis y crítica de Efecto vudú de Edgar Omar Avilés, una obra que somete a tensión las nociones teóricas y de crítica literaria en tiempos posmodernos y de globalización.

\section{Hacia una comprensión de lo fantástico}

Sin duda, la expresión literaria es una forma de discurso que se aparta del uso pragmático del lenguaje, es decir, que su propósito va más allá de lo que se denomina "lenguaje cotidiano", el cual se caracteriza por buscar generar "resultados, influir en actos y actitudes" (Warren y Wellek 29). Por el contrario, lo literario tiende a lo ambiguo y a lo connotativo, evita ser designativo y aspira a lo expresivo (Warren y Wellek 28). Para ello tensa el lenguaje y explora sus posibilidades expresivas-semánticas y se alimenta del mundo simbólico latente. Más aun: como afirma Roman Ingarden, la obra de arte literaria es una entidad cuasi-juicial, en la que se representan aspectos del mundo fáctico sin por ello dejar de ser una representación verosímil (263).

Lo literario está, metafóricamente hablando, habitado de fantasmas: se trata de entidades que se materializan a través del lenguaje escrito y que adquieren forma a través de la acción lectora. Aquí es donde conviene hacer énfasis: si bien en la expresión literaria se pueden hallar personajes, lugares y objetos cuya existencia logra verificarse en el universo fáctico — lo que daría lugar a lo que se llama "obras de carácter realista"-, esta se conforma también a partir de seres y circunstancias que se apartan del plano en el que se desarrolla nuestra existencia. Estas últimas formas del discurso literario se ubican dentro de formas de registro que se denominan "lo maravilloso" y "lo fantástico".

De acuerdo con Omar Nieto, "lo maravilloso" y "lo fantástico" en lo literario han sido confundidos. Nieto señala: "Lo feérico (lo 
maravilloso) y lo fantástico propiamente dicho son dos polos que se excluyen, rompiendo así con la idea popular de que tales palabras son sinónimas" (67); y abunda señalando que:

lo maravilloso implica encantamiento, término que demanda por necesidad someterse a la fuerza sobrenatural, ser parte de ella y no cuestionarla. Rosalba Campra lo aclara aún más: '(si) la presencia de ejemplos sobrenaturales no provoca escándalo, se vuelve al ámbito de lo maravilloso'. (67)

Lo fantástico, para Nieto, es una estrategia textual que se caracteriza por la representación de dos elementos que tienden a oponerse: "la cotidianidad ... y un elemento extraño, que viene a romper la normalidad o el orden establecido" (60). En lo fantástico siempre existe una ruptura, la irrupción de un elemento extraño dentro del universo representado.

De acuerdo con Nieto, lo fantástico es un "sistema", un modus operandi que se manifiesta en diversos marcos culturales e históricos y que depende "más de una estrategia textual que de la reacción o no reacción por parte del lector" (52). Además, el sistema de lo fantástico es una forma de expresión que va más allá de un catálogo de temas y estructuras narrativas preestablecidas; por el contrario, es una manera de articular el discurso narrativo, que "permite al menos tres formas de conjugar los elementos que interactúan y que se convierten a la sazón en tres paradigmas: clásico, moderno y posmoderno" (54).

Nieto considera que el paradigma de lo fantástico clásico se distingue por representar la irrupción de fuerzas externas al contexto narrativo y que encarnan el mal (103). Por otra parte "sólo hay una verdad absoluta, una verdad única . . . un sistema de valores que es acechado por el elemento sobrenatural-extraño-lo otro y que en manos de éste puede llegar a ser aniquilado" (107). Aquí pueden ubicarse obras como Frankenstein de Mary Shelley y Drácula de Bram Stoker. En la primera, la creatura, que es el resultado de un experimento científico "fallido", amenaza el orden preestablecido por lo "natural" con su existencia y con su solicitud de una compañera que 
sea de su mismo linaje. En el segundo, el vampiro se cierne como una sombra sobre vidas inocentes de las cuales se alimenta y a las que corrompe.

Lo fantástico moderno se caracteriza por representar "un sistema de valores que ya no es absoluto, hay varias posibles verdades dentro de él" (Nieto 107); ello implica una ruptura con respecto a lo fantástico clásico porque abre la puerta a otras "verdades" dentro del texto. Aquí, el origen de la inestabilidad ya no es una fuerza externa a los personajes, sino una que emana desde adentro, de modo que:

el inconsciente es un mundo siniestro ..., abyecto ..., que emerge y suplanta el estado de lo real, para instaurar, en el lugar de él, una naturalización de lo sobrenatural, registrando en este nuevo estado, la falta de problematización del hecho extraño. (Nieto 142)

En este sentido, los horizontes de lo fantástico y lo maravilloso se unen, porque, como señala Nieto, lo sobrenatural se normaliza (147). En este ámbito podemos ubicar los Mitos de Cthuluh de H. P. Lovecraft, La Guerra de los Mundos de H. G. Wells o Las crónicas marcianas de Ray Bradbury. En ellas lo ajeno, expresado por medio de las fuerzas antiguas y prehistóricas en el caso de Lovecraft, o de seres de otros planetas en la obra de Wells y de Bradbury, también son extensiones del mundo interior de quienes tienen contacto con ellos; así, las fuerzas "externas" y las "nativas" se entremezclan. Finalmente, se encuentra lo fantástico posmoderno: una forma de expresión que está ligada a lo que Linda Hutcheon llama "poética de la posmodernidad".

Omar Nieto da rasgos muy generales de lo posmoderno, por tanto se vuelve necesario abundar un poco más sobre el tema. Para ello recurriré a los planteamientos de Hutcheon: lo posmoderno es

una abierta y siempre cambiante estructura teórica que, simultáneamente, nos permite ordenar tanto nuestra comprensión de la cultura y nuestros procedimientos críticos ... es una manera de hablar — un discurso-y al mismo tiempo 
un proceso que implica formas de pensamiento . . . (14; la traducción es mía) ${ }^{1}$

En síntesis, y en palabras de Hutcheon:

... es el proceso de la construcción del producto; es ausencia dentro de presencia; es dispersión que necesita centralizarse con el fin de ser dispersa; es el idiolecto que aspira, pero reconoce que no puede, llegar a ser el código maestro; es la inmanencia que niega y, al mismo tiempo, desea la trascendencia. En otras palabras, la posmodernidad se mueve en una lógica de 'ambos/y', y no en una del 'sin/o'. ${ }^{2}$ (49; la traducción es mía)

De regreso a los planteamientos de Omar Nieto, se recuperan las principales características de la estética posmoderna:

Hibridación, . . . simulacro, metaficción, intertextualidad, ludicidad, . . . ironía, arcaísmo, desarraigo, fractalidad, palimpsesto, deconstrucción, coexistencia, tiempo no-lineal, multiplicidad de cosmovisiones, pastiche, collage, eclecticismo, relativismo, hiperrealidad. (226)

Cada una de estas estrategias inciden en lo fantástico posmoderno, en el que se "relativiza los estatutos de realidad y [lo] sobrenatural para hacerlos itinerantes dentro de la estructura textual" (234). Más adelante, Nieto afirma: "En los relatos fantásticos posmodernos, la ficcionalidad se convierte en el significado dominante del texto.

1 "an open, ever-changing theoretical structure by which to order both our cultural knowledge and our critical procedures . . . It is both a way of speaking -a discourse- and a cultural process involving the expressions of thought ..." (Hutcheon 14).

2 " . . is the process of making the product; it is absence within presence, it is dispersal that needs centering in order to be dispersal; it is the idiolect that wants to be, but knows that cannot be, the master code; it is immanence denying yet yearning for transcendence. In other words, the postmodern partakes of a logic of 'both/and', not one of 'either/or"' (Hutcheon 49). 
Constituyen en sí mismos una teoría de la ficción, pero sobre todo una teoría de lo fantástico" (272). Dentro de este paradigma se encuentra Efecto vudú de Edgar Omar Avilés.

\section{Narrativa fantástica en México: breve panorama}

¿Cuál es el estado de la cuestión de la narrativa fantástica en México? Históricamente ha existido una minusvaloración de esta forma de expresión, de acuerdo con fuentes como Maricruz Castro Ricalde (2012) o Alberto Chimal (2017), quienes señalan que se ha negado el valor de lo fantástico dentro del canon literario mexicano. Los dos concuerdan en que esta forma de expresión no ha sido bien vista por los temas que aborda — mundos imaginarios, circunstancias que se apartan del realismo, seres mágicos- y por alejarse de las corrientes ideológicas predominantes, que en diversos momentos optaron por concebir lo literario como un instrumento moralizante y educativo, o como medio por el que se tenían que plantear respuestas a las problemáticas más urgentes de la sociedad como la pobreza, la justicia o la construcción de una identidad nacional.

Alberto Chimal señala que la concepción de poca valía de lo fantástico ha partido más de prejuicios de la crítica y de otros aspectos de carácter extraliterario, y lamenta que estos factores hayan impedido hacer una justa valoración de esta forma de discurso. Señala:

En tiempos recientes, el adjetivo 'fantástico' se ha utilizado para etiquetar poco más que una o dos variedades de narraciones: aquellas en las que aparecen dragones, guerreros con espadas y elfos de arco y flecha embarcados en peligrosas misiones, a imitación del Señor de los Anillos, de J. R. R. Tolkien, o bien las que tienen niños magos, provistos de poderes que deben aprender a utilizar, siguiendo la tendencia que marcaron las novelas de J. K. Rowling sobre Harry Potter. (7)

Independientemente de la discusión abierta por Chimal y otros más, lo fantástico es un sistema que va más allá de fórmulas y temas preestablecidos, aspectos que indudablemente entran en el terreno 
de los prejuicios y que son etiquetas útiles para el mercado editorial. La valía de esta forma de discurso radica en su modo de tensar el lenguaje para expresar lo "anómalo", así como en su particular manera de simbolizar y de problematizar la experiencia humana, nuestra particular circunstancia como sociedad, con todo y nuestras transformaciones, imaginarios y cosmovisiones. Forma, fondo y tema son algunas de las oportunidades que se presentan en este tipo de registro textual, llevados al terreno de lo creativo, la exploración de circunstancias extremas y la materialización de "lo Otro" y de aquello que se percibe como las fuerzas que amenazan y desestabilizan el universo conocido, ya sea por medio de la metáfora o la alegoría. Por ello es importante reevaluar la presencia de lo fantástico en nuestra tradición literaria a partir de las observaciones de Omar Nieto - recordemos que es un modus operandi que está plasmado en el texto, en el que la realidad representada es sometida a crisis por un elemento abyecto, ajeno- - De esta manera, descubriríamos que lo fantástico tiene profundas raíces en México que pueden ubicarse desde, por ejemplo, el Primero sueño de Sor Juana Inés de la Cruz, y está presente a través de una larga lista en la que aparecen casos como El fistol del diablo de Manuel Payno, las Historias de vivos y muertos de Artemio de Valle Arizpe, Pedro Páramo de Juan Rulfo, Aura de Carlos Fuentes, textos de Elena Garro como La semana de colores, la cuentística de Inés Arredondo, los escritos de José Emilio Pacheco como "Langehaus", "Tenga para que se entretenga" o "Las batallas en el desierto" y los relatos de Juan José Arreola, Salvador Elizondo, Francisco Tario... Así, tendríamos una lista que se extendería hasta el presente, donde hallaríamos nombres como el de David Toscana, Luis Humberto Crosthwaite, Norma Lazo, Gerardo Horacio Porcayo, Ignacio Padilla, Karen Chacek, Daniela Tarazona, Yuri Herrera, Bernardo Bef Fernández, Bernardo Esquinca, Carlos Alvahuante, Alberto Chimal, Edgar Omar Avilés, entre varios creadores recientes más. 


\section{Efecto Vudú y lo fantástico posmoderno}

Edgar Omar Avilés nació en Morelia, Michoacán, en 1980. Su producción narrativa se concentra primordialmente en el género del cuento. Algunos de sus volúmenes de narraciones cortas son La noche es luz de un sol negro (2007), Embrujadero (2010), Luna cinema (2010) y No respiramos: inflamos fantasmas (2014). En el terreno de la novela cuenta con dos libros: Guiichi (2008) y Efecto vudú (2017). Como escritor ha recibido varios reconocimientos como el Premio Nacional de Cuento de Bellas Artes San Luis Potosí (2008) y el Premio Nacional de Cuento Joven Comala 2011, por su obra Cabalgata en duermevela.

La narrativa de Edgar Omar Avilés tiene la particularidad de construirse con base en la brevedad, la contundencia y lo fantástico. En sus escritos existe un diálogo con diversos aspectos del mundo contemporáneo. Por ejemplo, en su cuento "Indocumentado" (2017) aborda el problema de la construcción de la memoria y la identidad a partir del fenómeno de la migración ilegal que va de Centroamérica y México hacia Estados Unidos, y en "La noche fósil" (2015) se cuestiona el avance tecnológico que se realiza con el único propósito de obtener ganancias sin atender las consecuencias. También en su producción existen narraciones de tipo metaficcional, como el cuento "Manzana" (2015), una reescritura paródica del cuento de "Caperucita roja" en tono de ciberpunk, o relatos como "Cuando no estamos, ¿de qué hablan las palabras?" (2015), en los que hay una reflexión sobre los límites y la plasticidad del lenguaje a través de recursos como la brevedad, la fragmentariedad y la hibridación de elementos ficcionales y aforísticos.

Otro aspecto notable de la obra de Avilés es que presenta una hibridación de géneros literarios, además de que abreva de referentes provenientes de distintos marcos culturales. Ello, en el conjunto, le da forma a un mundo en el que se hacen evidentes diferentes grados de correlación espacial-temporal. Dicho rasgo ubica esta producción dentro de los registros de la poética posmoderna.

Efecto vudú conjunta estrategias de creación propias de la poética de la posmodernidad: es una ficción que se alimenta de veinte 
microrrelatos y cinco ramas narrativas que se van enlazando a lo largo de los veinte capítulos que conforman el texto. Otro de sus elementos es la presencia de lo fantástico en su faceta posmoderna: las historias se ramifican y representan un mundo inestable, sometido al caos, donde se relativizan las nociones de "realidad" fáctica y lineal. Por otro lado, las acciones individuales y las emociones son los ejes por los que el cosmos es sometido a tensión. Asimismo se erigen en factores que fracturan y dan forma a las líneas del tiempo y la noción de "Historia". El relato, además, abreva de referentes culturales diversos, como la cultura afroantillana y aspectos provenientes de los pueblos asiáticos. Finalmente, se observa la presencia de recursos como la intertextualidad, la metaficcionalización, la ironía y la parodia.

$\mathrm{Al}$ inicio de Efecto vudú se presentan dos epígrafes y una dedicatoria que tienen el fin de preparar el terreno para la irrupción de lo fantástico, de abrir la posibilidad de reflexionar sobre el papel que tienen la imaginación y lo fabuloso en el mundo de lo real, así como de señalar el carácter complejo y profundo que constituye el conocimiento del cosmos y nuestra posibilidad de aprehenderlo. El primer epígrafe es de J. G. Ballard, narrador inglés de ciencia ficción y de obras que exploran los límites de lo racional a través del mundo interior. Dice:

Creo en el poder de la imaginación para rehacer el mundo, para liberar la verdad que llevamos adentro, para sujetar la noche, para trascender la muerte, para hechizar las autopistas, para congraciarnos con los pájaros, para asegurarnos las confidencias de los locos. (7)

En la misma página aparece una frase de Pierre Tehillard de Chardin, científico y filósofo jesuita de origen francés que buscó reconciliar los principios de la teología con los de la ciencia: "En la escala de lo cósmico sólo lo fantástico tiene posibilidades de ser verdadero.” Dos páginas más adelante aparece la siguiente dedicatoria: "Para todos aquellos que imaginando conquistan, habitan y nos heredan mundos gloriosos" (9). Por estas invocaciones, es claro que 
este escrito, más que constituir una apología de la razón, convoca a la fe, la imaginación y las capacidades creativas del lector.

Los veinte microrrelatos que conforman la novela, así como las cinco grandes ramas narrativas, dan continuidad a la idea respecto a la forma en que la imaginación y lo fantástico abren las puertas a la reconfiguración del cosmos: son espacios por los que el lector observa cómo este universo se diversifica y genera múltiples posibilidades del Ser. Estos microtextos tienen como título "Las otras vidas de Ychi”. La novela inicia con el siguiente microtexto:

En el siglo XXV antes de Cristo, en Egipto, Ychi fue un afamado amaestrador de piedras. Su talento se alimentó de paciencia, sensibilidad para hacerse entender y sabiduría para propinar recompensa o castigo. Así logró educarlas para que formaran pirámides. Las piedras hoy en día aún aguardan su señal para moverse. (12)

El siguiente microcuento es este:

En el siglo VII, en Grecia, Ychi fue soñado como una rama de pasto por una cabra recién nacida. Conforme la cabra creció, continuó soñándolo. La cabra, confinada en un pequeño establo, daba suficiente leche a sus dueños, por lo que nunca fue considerada para sacrificio, y así llegó a vieja. La cabrita murió soñando que aún era joven y que brincaba, libre, en el enorme y espléndido pastizal en que Ychi se había convertido. (18)

Por los microrrelatos observamos el modo en que grandes momentos de la civilización alternan con historias mínimas, como sucede en el caso de las pirámides de Egipto, cuyo origen es representado como un acto de magia en donde, además, las piedras son "domesticadas" como si fueran seres vivos. Y más aun: los animales y las plantas son humanizados y aparecen como entes que tienen atributos como la voluntad, la memoria y la capacidad de fabular.

Los microrrelatos conforman un sistema narrativo que problematiza la idea de la continuidad histórica como una linealidad sin rupturas, ya que el factor "Ychi" asume múltiples atributos en va- 
riados marcos temporales y espaciales: es un mago egipcio, un pastizal griego, un cigarrillo filósofo, una sopa lituana especial, un chef francés martirizado, un científico brasileño, entre muchos entes más. Por otro lado, es peculiar la manera en que estas anécdotas evocan lo global: se habla de Lituania, Francia, Grecia, Australia, Brasil, Italia, Uruguay, México, entre otros países. Ello muestra que existe una disolución de las fronteras políticas y culturales, de modo que, al final, lo relevante es apuntar hacia lo universal: la experiencia humana, más allá de los referentes locales. Esta idea de fracturar las nociones de lo central y hacer una mirada amplia del globo a partir de historias mínimas es otro rasgo de la poética de la posmodernidad (Hutcheon 49).

Como se ha mencionado, la novela además se compone por cinco grandes ramas narrativas. Si se ordenan de forma cronológica, tenemos que la primera sería la historia de un Ychi que es un mago-científico, quien presenta un decadente espectáculo de circo que consiste en resucitar cadáveres; ello sucede en España, en el siglo XIX. La segunda sucede durante los años 40 del siglo XX en Haití y tiene como protagonista a Madame Garcell, una gran sacerdotisa vudú que hace todo lo posible por recuperar el alma de su hijo, Ychi, quien, por accidente, acabó transformado en zombi. La tercera rama narrativa se ubica en el siglo XXIII, en un mundo tecno-orgánico llamado "Ychi"; ahí un trío de niños lucha por sobrevivir a una serie de pruebas semejante a Los juegos del hambre, al mismo tiempo que trata de recuperar la memoria. La cuarta rama acontece en Japón, en el siglo XXV: el mundo está contaminado por la radiación, lo que provoca que no haya suficientes alimentos. Además de la devastación ecológica, en los cielos se desarrolla una guerra interminable entre fantasmas de robots y humanos; solo sobrevive un puñado de robots melancólicos que poco a poco dejan de funcionar y un reducido grupo de humanos, entre los que se encuentra Ychi. Por último, la quinta rama se ubica en Rusia, en el siglo XXVIII; ahí Ychi es un zar sabio y benevolente que gobierna un mundo diverso, habitado por seres de papel.

La novela tiene como ejes la rama narrativa ubicada en Haití en los años 40 del siglo XX y la de Rusia en el siglo XXVIII. Son los puntos donde se genera un duelo de magia entre Madame Garcell 
y los habitantes del mundo de papel: la primera, recordemos, trata de alterar el pasado para salvar a su hijo, mientras que los segundos sufren los efectos de la ruptura de continuidad del tiempo y hacen lo posible por evitar su aniquilación. En los demás universos se dejan sentir los efectos de estos duelos por medio de alteraciones en la continuidad temporal y en el traslado de seres de los diferentes mundos. Aquí algunos ejemplos: Ychi, el mago-científico español del siglo XIX resucita un cadáver que alberga el alma de sí mismo: ha viajado en el tiempo y, ante sí mismo, vaticina cómo habrá de morir (161-166). En el mundo tecno-orgánico de Ychi, en el siglo XXIII, hay un concilio de almas presidido por Mantis, un fantasma de papel que viene del siglo XXVIII, quien predica la posibilidad de la materialización de las almas por medio de la fe y la voluntad (93101). Un grupo de soldados nazis, en 1943, desaparece de un campo de batalla de manera misteriosa y es trasladado al siglo XXVIII, a la Rusia gobernada por el zar Ychi; ahí se iniciará la lucha cósmica final entre las fuerzas convocadas por Madame Garcell y la magia de los seres de papel (123-130).

Como puede observarse, de nueva cuenta, hay una evocación a los principios de la poética de la posmodernidad al fracturarse las nociones provenientes del pensamiento moderno, como las de linealidad temporal y espacial, y al someter a crisis los principios de "identidad", "progreso", "certeza histórica", "centralidad" y "razón”. En cuanto a lo identitario, en la obra se hace énfasis en que la unidad es reflejo de un todo que va más allá de las individualidades y que tiende redes en el tiempo. Respecto al cuestionamiento de la idea de progreso, los escenarios del pasado, el presente y el futuro son el resultante de circunstancias cambiantes: no existe un mejor futuro. Por el contrario, el presente se constituye a través de conflictos existentes en el pasado y por la irrupción de fuerzas ubicadas en el futuro. La Historia no brinda certezas acerca de un mejor mañana y no es el testimonio de la superación de los modelos anteriores; es, por el contrario, un flujo de hechos que encierra rupturas, disonancias y contradicciones. La centralidad es puesta en cuestión al subordinar lo macro a lo micro - la suerte de las tropas del Tercer Reich puestas al servicio de una hechicera vudú-, al generar 
uniones carnavalescas entre géneros narrativos —el microrrelato con la novela, por ejemplo- y entre referentes culturales, donde lo mexicano es prácticamente un segmento menor y se colocan en un primer plano elementos afroantillanos —nociones animistas y rituales vudú - y orientales — la idea del karma, la posibilidad de las reencarnaciones y el hecho de que el mundo del futuro sea de papel y habitado por seres de origami-, así como al presentar diferentes modos de articulación del "sistema de lo fantástico" — narrativa de hadas, distopías, ciencia ficción y de horror- Finalmente, la noción de "razón" se cuestiona al poner como elementos detonadores de la diégesis el amor maternal, la fe y la voluntad de existir, a través de lo mágico y lo mítico, en suma: lo fantástico.

\section{Conclusiones}

En los últimos años ha habido una creciente producción de escritos con clara tensión hacia lo fantástico. Inclusive algunos autores han realizado esfuerzos por difundirlo y porque sea reconocido por la crítica. Alberto Chimal (2017), Bernardo Fernández BEF (2016) y Rodolfo J. M. (2014) son algunos autores que han elaborado antologías de lo fantástico, escrito al respecto y discutido sobre el asunto en diversos espacios.

Alberto Chimal es una de las figuras que más se ha destacado en el terreno de la producción, difusión y formación de escritores en el ámbito de lo fantástico. Ha impulsado la idea de crear una nueva noción, "literatura de la imaginación", para evitar los prejuicios que pesan sobre los textos de corte fantástico. Este concepto, lamentablemente, carece de sustento teórico, ya que su principal argumento es diferenciar las producciones "legítimas" de las "marcadas" por el mercado y el prejuicio. Empero, es notable cuando Chimal reflexiona por qué la crítica y ciertos círculos de lectores a lo largo del tiempo se han resistido a aceptar como válida esta forma de discurso: es el resultado de la primacía que el pensamiento moderno le ha dado a los principios de racionalidad y positividad; esto condujo a la creación de la dicotomía entre lo real y lo irreal, la razón y las emo- 
ciones, la Historia y el mito (Herrera 185). Por ello, ciertas formas literarias, al no ceñirse a lo "fáctico" y lo "utilitario" fueron despreciadas y consideradas de poca valía estética y cultural. Este velo histórico, en el caso mexicano, no ha facilitado la justa apreciación de lo fantástico en nuestras letras, y señala: "Muchas personas sostienen que la narrativa mexicana rechaza la imaginación 'por naturaleza' y tiene como impulso esencial describir al mundo tal cual es. Esto no es cierto" (Chimal 10). Entonces, Chimal hace un recuento de la rica producción de lo fantástico que va desde el Primero sueño de Sor Juana Inés de la Cruz — “. . . un poema narrativo, muy intrincado, en el que la conciencia se escapa del mundo hacia una especie de 'plano superior' en busca de la divinidad" (10)—, pasando por el siglo XIX donde hubo una gran proliferación de narraciones breves “. . . en las que se imaginaba el mundo del futuro, se replicaban y rehacían leyendas populares, etcétera” (10), hasta tiempos recientes, donde detecta creadores que, más que eventuales productores de narrativa fantástica, lo han sido de modo frecuente, como es el caso de Emiliano González, Carlos Fuentes, Pablo Soler Frost, Carmen Boullosa o Mauricio Molina (10-11). A esta lista, como se mencionó líneas atrás, bien habría que agregar nombres como el de Artemio de Valle Arizpe, Juan Rulfo, Juan José Arreola, Elena Garro, Inés Arredondo, entre otros más.

En el caso mexicano, Chimal propone otra aproximación al problema de la aceptación de lo fantástico como parte de nuestra tradición literaria: acusa la fuerte presencia que, a lo largo de nuestra historia, ha tenido la ideología autoritaria, la cual percibe en lo "onírico" y lo "irreal" una expresión que cuestiona al poder. Afirma:

Aunque las obras utilizan la imaginación fantástica no tienen necesariamente un compromiso político, el hecho que se refieran a lo imposible, a los límites de una idea de lo real, invita a pensar en cómo entendemos —o cómo se nos hace entender - la realidad. Y esta reflexión irrita al pensamiento autoritario porque incita a salir del conformismo, de la docilidad... (11) 
Más allá de las discusiones sobre las circunstancias sociales e intelectuales que han impedido apreciarlo en su justa medida, bien vale la pena hacer una reevaluación de lo fantástico desde la teoría literaria. Bajo esta óptica, los textos escritos en esta forma de discurso no juegan su valía por el tema que abordan sino por sus elementos intrínsecos; es decir: en la medida en que los textos son capaces de generar un equilibrio entre los diversos estratos que los conforman — sonidos verbales, unidades de sentido, objetividades representadas, aspectos esquematizados y vicisitudes-, como lo plantea Roman Ingarden (Nyenhuis 16-23).

La valoración de los textos no "emana" únicamente de los atributos intrínsecos de los escritos, pero de estos se puede partir para la evaluación crítica del texto. Como también señala Ingarden, la obra de arte literaria demanda la participación del lector real para concretizarse, y es él quien pone en juego su existencia y cosmovisiones para este fin. De esta manera, el acto de lectura es un diálogo con los escritos que somete a tensión el modo como entendemos, por ejemplo, lo valioso, lo importante e, inclusive, las nociones de lo que "debería ser" y "hacer" el arte y lo literario (Ingarden 44-47). Ello complejiza el modo en que apreciamos las obras escritas. Además, explica las oscilaciones y las constantes en cómo se construyen nuestros cánones literarios y, por extensión, el puesto que ocupa lo fantástico en nuestras letras.

Las circunstancias actuales también han jugado un rol importante en el desarrollo y revisión del papel de lo fantástico en nuestra cultura: existe un mayor acceso a obras y contenidos producidos en otras latitudes, que son relativamente fáciles de consumir a través de los medios digitales. De este modo, lectores y autores tienen contacto con otros parámetros estéticos, temáticos y canónicos de lo literario, lo que conduce a buscar vías de producción y diálogo diferentes a las establecidas por las tradiciones locales. Por otra parte, el espíritu de la posmodernidad ha impulsado la revisión de los archivos cognitivos y de cómo se han construido los cánones, lo que ha provocado desplazamientos tanto en el modo de hacer y apreciar el lenguaje y sus estructuras, como en el modo de crear obra. 
No puede obviarse, por supuesto, que la producción narrativa de lo fantástico es una ventana por la que autores y públicos lectores de inicios del presente siglo dialogan con un mundo hipervinculado gracias a las tecnologías de la información y a la circulación masiva de datos. Gianni Vattimo ya había señalado en los años 90 que las sociedades de la información no son más ilustradas ni transparentes; por el contrario, tienden a la complejidad y al caos (Vattimo 12). Recordemos que en la narrativa de lo fantástico se singulariza la irrupción de "lo Otro", "lo extraño" que desestabiliza el orden del universo representado; y en la vida actual, el cambio de paradigmas, la multiplicidad de voces y perspectivas sobre un mismo hecho, inclusive la sensación de inestabilidad del presente generada por fuerzas ajenas a la esfera de influencia de la propia voluntad son el terreno propicio para la complejidad y el caos descrito por el pensador italiano. Entonces, el juego imaginativo que plantea la producción de escritos de lo fantástico es propicio para el desarrollo creativo de búsqueda de respuestas ante escenarios de incertidumbre. Esta es una de las virtudes de la propuesta de Edgar Omar Avilés, narrador que por medio de los matices, la precisión y economía del lenguaje, en conjunto con la hibridación de géneros y la experimentación de registros narrativos que toma lo fantástico como eje principal, ha comenzado a construir una propuesta que poco a poco ha ido madurando y que desemboca en Efecto Vudú.

Efecto vudú, además de las líneas señaladas en el presente artículo, es poseedora de una valiosa y amplia riqueza semántica y lingüística, de complejidad estructural y de otros atributos literarios que bien valdría la pena seguir explorando a través de los estudios literarios y del abordaje del pensamiento contemporáneo. Es una ficción que invita a la reflexión sobre la importancia de las historias mínimas, del modo en que lo intangible y lo tangible se rozan, se unen e influyen en la esfera de lo humano y su actuar en el mundo; del delicado orden de las cosas en un mundo de interacciones y redes; de las urdimbres de la memoria y de cómo la Historia es cuestionada, mostrándola como un tejido con oquedades, silencios, plegamientos, recursividades, olvidos y ecos que se prolongan en el tiempo. Tenemos la certeza de que un trabajo más en profundidad 
e interdisciplinar, permitirá ampliar el espectro de visión de esta narración y, a la vez, ayudará a poner al día nuestra comprensión y apreciación de la producción literaria hispanoamericana reciente.

\section{Fuentes citadas}

Castro Ricalde, Maricruz, et. al. Inquietantes inquietudes: Tres décadas de literatura fantástica. Instituto Mexiquense de Cultura, 2012.

Chimal, Alberto. Presentación. La tienda de los sueños: un siglo de cuento fantástico mexicano. Ediciones SM, 2017, pp. 7-13.

Fernádez, Bernardo. "La cofradía de los fantasmas". Presentación. Los viajeros. 25 años de ciencia ficción mexicana. Ediciones SM, 2016, pp. 7-24.

Hutcheon, Linda. A Poetics of Postmodernism. Roultedge, 2000.

Ingarden, Roman. La obra de arte literaria. Taurus / Universidad Iberoamericana, 1998.

J. M., Rodolfo. Presentación. El abismo. Asomos al terror hecho en México, Ediciones SM, 2014, pos. 19-84.

Nieto, Omar. Teoría general de lo fantástico. Universidad Autónoma de la Ciudad de México, 2015.

Nyenhuis, Gerald. Prefacio. La obra de arte literaria, por Roman Ingarden. Taurus / Universidad Iberoamericana, 1998, pp. 15-24.

Vattimo, Gianni et al. En torno a la posmodernidad. Anthropos, 2003.

Vattimo, Gianni. "Posmodernidad: ¿una sociedad transparente?". Vattimo, et al., En torno a la posmodernidad, pp. 9-19.

Warren, Austin y Rene Wellek. Teoría literaria. Gredos, 2002. 